\title{
Using model predictive control in a water infrastructure planning model for the
} Zambezi river basin

Payet-burin, Raphaël; Kromann, Mikkel T.; Pereira-Cardenal, Silvio; Marc Strzepek, Kenneth; BauerGottwein, Peter

Published in:

Water: Connecting the World

Publication date:

2019

Document Version

Peer reviewed version

Link back to DTU Orbit

Citation (APA):

Payet-burin, R., Kromann, M. T., Pereira-Cardenal, S., Marc Strzepek, K., \& Bauer-Gottwein, P. (2019). Using model predictive control in a water infrastructure planning model for the Zambezi river basin. In Water:

Connecting the World: IAHR 38th World Congress - Panama 2019 (pp. 4057-4062). CRC Press.

\section{General rights}

Copyright and moral rights for the publications made accessible in the public portal are retained by the authors and/or other copyright owners and it is a condition of accessing publications that users recognise and abide by the legal requirements associated with these rights.

- Users may download and print one copy of any publication from the public portal for the purpose of private study or research.

- You may not further distribute the material or use it for any profit-making activity or commercial gain

- You may freely distribute the URL identifying the publication in the public portal 


\title{
USING MODEL PREDICTIVE CONTROL IN A WATER INFRASTRUCTURE PLANNING MODEL FOR THE ZAMBEZI RIVER BASIN
}

\author{
RAPHAËL PAYET-BURIN (1), MIKKEL KROMMAN (2), SILVIO PEREIRA-CARDENAL (3), KENNETH \\ STRZEPEK ${ }^{(4)} \&$ PETER BAUER-GOTTWEIN (5) \\ ${ }^{(1,5)}$ Department of Environmental Engineering, Technical University of Denmark, Kgs. Lyngby, 2800, Denmark, \\ rapp@env.dtu.dk \\ $(1,2,3)$ COWI A/S, Kgs. Lyngby, 2800, Denmark, \\ (4) MIT, Joint Program Sci \& Policy Global Change, 77 Massachusetts Ave, Cambridge, MA 02139, USA,
}

\begin{abstract}
Hydroeconomic optimization models considering the inter-relations in the water-energy-food nexus are potential tools to evaluate water infrastructure and policy development that will contribute to multiple Sustainable Development Goals. However, most of these models are deterministic and assume perfect foresight. Thus, the optimal management decisions are found with perfect knowledge of future conditions, which might bias the economic evaluation of infrastructure investments. We show how the Model Predictive Control (MPC) framework can be used to overcome the perfect foresight assumption. By implementing the MPC framework in WHAT-IF, a perfect foresight hydroeconomic optimization model, we show how MPC leads to more realistic simulated reservoir operations and consequently to a more realistic valuation of investments. To evaluate the impact of the perfect foresight assumption, we evaluate infrastructure investments in the Zambezi river basin with and without the MPC framework. We find significant differences (up to 12\%) between the perfect foresight and MPC frameworks when estimating the value of hydropower and irrigation investments. By carrying out the analysis for four different climate change scenarios, we find that the impact of the perfect foresight assumption is particularly important in a water scarce context.
\end{abstract}

Keywords: Water infrastructure investments, Water-Energy-Food Nexus, Hydroeconomic optimization models, Model Predictive Control

\section{INTRODUCTION}

Ecosystem preservation, hydropower and irrigation development will contribute to multiple Sustainable Development Goals (United Nations, 2015), while potentially competing with each other. Therefore, water infrastructure development plans must consider the interdependencies within the water-energy-food nexus (Albrecht et al., 2018).

To represents the interactions within the nexus, one strategy consists of linking existing models representing the various sub-systems of the nexus: the CLEWS framework (Howells et al., 2013) combines the WEAP model (Yates et al., 2005) for water management, the LEAP model (Heaps, 2016) for the energy system, and the GAEZ model (Fischer et al., 2002) for the agriculture. Similarly, (Cervigni et al., 2015) combines WEAP and OSeMOSYS (Howells et al., 2011) to assess the impact of climate change on water infrastructure in Southern Africa. Coupling models simplifies communication among stakeholders who can keep using the tools they have become familiar with and permits a more detailed representation of single systems. In simulation frameworks, the system management is calculated for each time step using allocation rules, with unknown future conditions. However, allocation rules are usually based on current or past socio-economic conditions and might not be economically optimal (Pereira-Cardenal et al., 2016).

Hydroeconomic optimization models associate an economic impact to each management decision, thus transform a complex multi-objective management problem into a simpler single-objective problem to find economically optimal management decisions (Harou et al., 2009). Stochastic Dynamic Programming (SDP) and Stochastic Dual Dynamic Programming (SDDP) have been used to represent water management problems and infrastructure evaluation (Davidsen et al., 2014; Pereira-Cardenal et al., 2016; Tilmant et al., 2012) while considering the stochastic properties of the water inflow. However, these methods can only represent a limited number of reservoirs and interactions. Hydroeconomic models representing numerous nexus interactions and multiple reservoirs (e.g. Kahil et al. (2018) and Khan et al. (2018)) often use linear programming and assume perfect foresight. Perfect foresight is a common approach to sectorial planning models (Keppo and Strubegger, 2010), where conversely to simulation models, the system is optimized over the whole planning period with perfect knowledge of the future. This means that optimization model anticipates future conditions such as droughts and adjusts by cultivating crops with lower water requirements or storing additional water. The optimization model thus overestimates investment performance or underestimates the need for investments. In 
reality, water planners and managers will not have perfect foresight, and will be limited by the availability and skill of existing forecasting systems. As droughts have important economic impacts (SADC et al., 2015), a more realistic way of modelling reservoir operations and agriculture decisions could improve the reliability of the results.

One way to implement limited knowledge about the future in an perfect foresight optimization modelling framework is to use Model Predictive Control (MPC) and iteratively solve the optimal management decisions in each time step using the forecast information available at the time of decision (Sahu, 2016). We implement the MPC framework in WHAT-IF (Payet-Burin et al. 2019) an open-source hydroeconomic optimization model, that links, in a holistic framework, representations of the water, agriculture, and power systems. We apply the methodology to the Zambezi river basin where large water infrastructure projects are planned to satisfy growing food and energy demands (World Bank, 2010). By comparing MPC and perfect foresight, we show how the perfect foresight assumption affects the valuation of the hydropower and irrigation development plan. We investigate in which cases the perfect foresight assumption could lead to biases in the evaluation of water infrastructure investments.

\section{METHODOLOGY}

\subsection{Perfect foresight hydroeconomic optimization model and study case}

The WHAT-IF model is an open-source hydroeconomic optimization model, linking, in a holistic framework, representations of the water, agriculture, and power systems (Payet-Burin et al. 2019). In WHAT-IF water management (e.g. water storage, release, and supply), energy management (e.g. power capacity construction, production, transmission, and supply) and agriculture management (e.g. crop choice, irrigation, transport, and supply) are decision variables which are solved to maximize the societal welfare, i.e. the sum of all consumer and producer surplus. The optimization approach is based on a perfect foresight formulation, as optimal decisions are found with full knowledge of the planning period.

We use the modelling framework and dataset of the Zambezi River Basin from Payet-Burin et al. (2019). The river basin is divided in 26 catchments with runoff and precipitation time series covering 40 years; the average yearly runoff is $114 \mathrm{~km}^{3}$. In each catchment domestic, agricultural, and industrial water demands are represent, as well as environmental flow constraints at the level of the main wetlands (Kafue flats, Baroste plain, and Mana pools) and the Zambezi delta. The main reservoirs of the river (Itezhi-Tezhi, Kariba, and Cahora Bassa dams) have an active storage capacity of $127 \mathrm{~km}^{3}$, and are the main consumptive water user of the river basin through evaporation losses. The agricultural water demand is calculated based on FAO 56, crop yields are based on FAO 33, and the crop choice is part of the optimization framework. Unlike in Payet-Burin et al. (2019), rainfed production and crop markets are not represented, only irrigated agriculture is represented and valuated at the farm level using FAO data (FAO, 2018). Hydropower plants are represented individually, assuming fixed head levels and using water-energy equivalent production coefficients. Thermal power is represented as aggregated production units per country. A power market per country is represented, including South Africa, with corresponding power demands. The power transmission network is represented with a transport model considering aggregated transmission lines between countries. A capacity expansion model represents additional investments in thermal and solar power, referred to as "generic power investments".

We use the reference "2010" scenario from Payet-Burin et al. (2019), considering the natural flooding environmental policy of $7000 \mathrm{~m}^{3} / \mathrm{s}$ in february. The evaluated water infrastructure development plan (PayetBurin et al. (2019), World Bank (2010)) considers 15 hydropower projects with $7.2 \mathrm{GW}$ of new operating capacity and 336000 ha of new areas equipped for irrigation, almost doubling the present irrigated area. To evaluate the MPC framework in different water scarcity levels, we consider four different climate change scenarios from Cervigni et al. (2015) as in Payet-Burin et al. (2019).

\subsection{Forecast generator}

The MPC framework requires information on future hydrological parameters. To generate these forecasts, we use an autoregressive Markov model (Loucks et al., 2005) for synthetic runoff time series generation:

$$
\mathrm{Q}_{\mathrm{t}}=\overline{\mathrm{Q}}_{\mathrm{m}}+\rho_{\mathrm{m}} \cdot \frac{\sigma_{\mathrm{m}}}{\sigma_{\mathrm{m}-1}} \cdot\left(\mathrm{Q}_{\mathrm{t}-1}-\overline{\mathrm{Q}}_{\mathrm{m}-1}\right)+\delta \cdot \sigma_{\mathrm{m}} \cdot \sqrt{1-\rho_{\mathrm{m}}^{2}}
$$

where $Q_{t}$ and $Q_{t-1}$ are the generated synthetic runoffs at time step $t$ and $t-1, \bar{Q}_{m}$ is the average runoff of the $m_{t h}$ month of the year corresponding to the time step $t, \sigma_{m}$ is the standard deviation of runoff in the $m_{t h}$ month and $\rho_{w}$ is the correlation coefficient between the runoff of the $m_{t h}$ and $m-1_{t h}$ months, $\delta$ is a random number with mean 0 and variance 1 . This method preserves the mean and the variance, using the current runoff as a starting point, it is used to generate runoff forecasts. To avoid the generation of negative inflows, the method is normally used with the log transform of the runoff. However, we use a net runoff data, considering the evaporative effect of wetlands, which results in negative runoff for some catchments, thus we can't apply the log transform. Therefore, we constraint the generated flows by the maximum and minimum observed in the catchment, this violates the conservation of the variance but generates more realistic flows. To simulate different 
qualities of forecasts, a perfect forecast horizon is added, varying from 1 (current month) to 12 months, where the actual future hydrological conditions are known. As a simplification, rainfall and reference evaporation forecasts are generated using climatology.

\subsection{MPC framework}

The MPC framework can be used to do real-time water management, in the sense that it determines "which decision to take now given currently available information about the future". However, here, the MPC framework is implemented to simulate a more realistic management of the water infrastructure than the one resulting from perfect foresight optimization runs, and thus, evaluate more accurately the potential economic impacts of water infrastructure investments and policies. Figure 1 summarizes the framework: At a given time step, an ensemble of hydrological forecasts is generated over the prediction horizon (e.g. 2 years). The optimal control actions over the prediction horizon (water storage, release, and supply) for each ensemble member are found using the perfect foresight model. The average of the first control actions (water storage, release, and supply for the current month) over the ensemble members is then implemented. At the next time step, the prediction horizon is moved, new forecasts are generated with updated knowledge of hydrological conditions, and the procedure is repeated until the end of the planning horizon is reached (e.g. 40 years). As the model contains a mix of monthly and yearly decision variables and outputs, the prediction horizon is flexible to always cover a complete year. Thus, for a prediction horizon of 2 years, the actual prediction horizon will vary from 13 to 24 months. The crop choice, and generic power capacity investment are yearly decision variables of the model that depend on hydrological conditions. The same approach as for water storage, release and supply is used for these decision variables, but for time steps that start a new year.

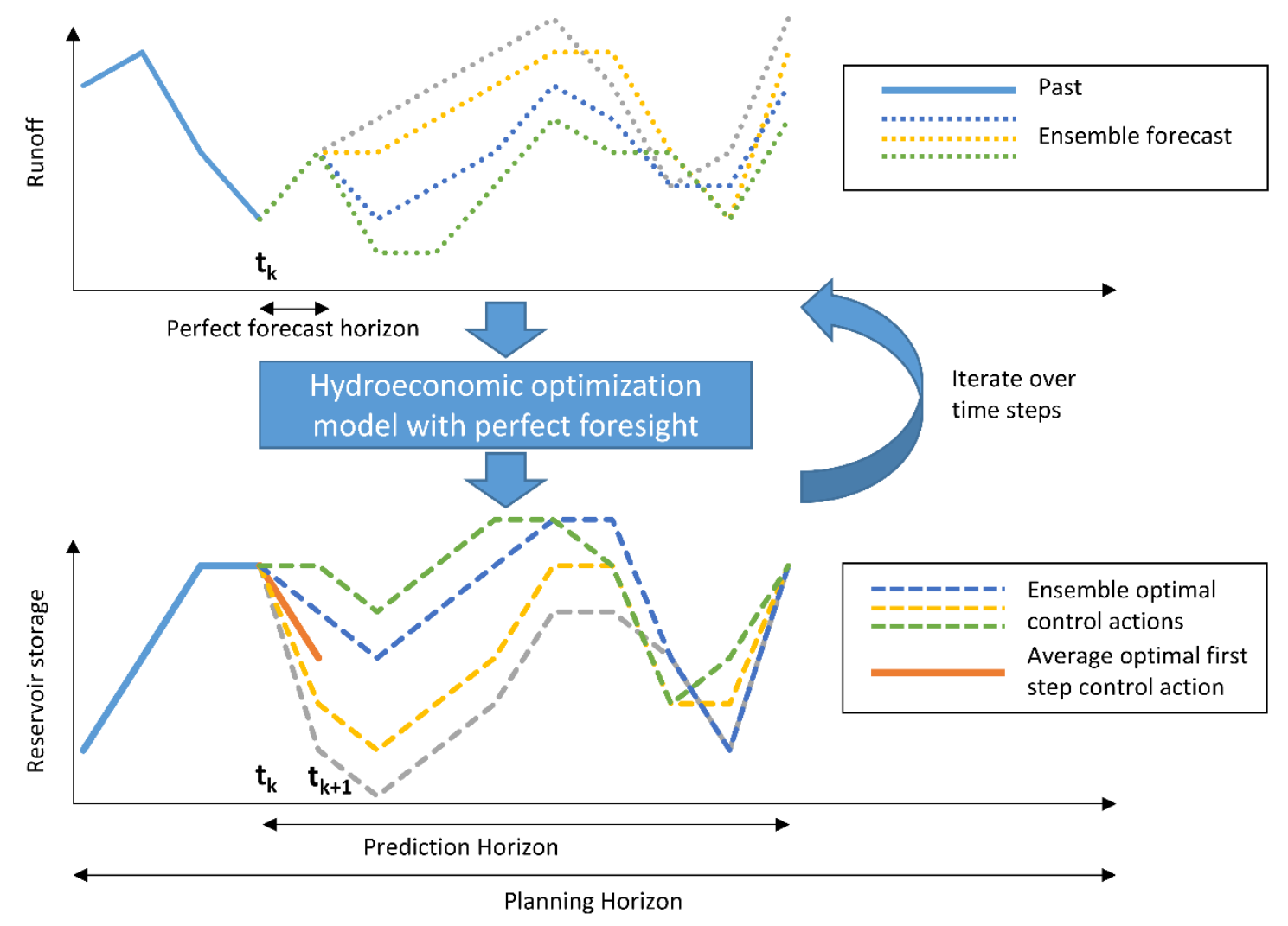

Figure 1. Model Predictive Control (MPC) framework.

\section{RESULTS AND DISCUSSION}

\subsection{Water management using MPC and perfect foresight}

Figure 2 shows the simulated reservoir operations in the Kariba reservoir for the perfect foresight (PF) and MPC (MPC1) framework over 20 years. With the perfect foresight assumption, the reservoir management anticipates future conditions: During the 1972-1973 drought (Bird and Shepherd, 2003) the perfect foresight management totally empties the reservoir anticipating the high flows of 1974; in 1978 the perfect foresight management starts accumulating water for the 1983 drought. In reality, water managers have limited knowledge of the future and will store more water to avoid future water shortages, this is better represented by the MPC framework (Figure 2). Note that the unrealistic water storage management for the perfect foresight framework 
is exacerbated by the fixed head assumption. Indeed, if the relation between the reservoir storage level and hydropower production was represented, even in the perfect foresight approach, the reservoir storage would be kept at a higher level to increase hydropower production.

\section{Kariba reservoir}

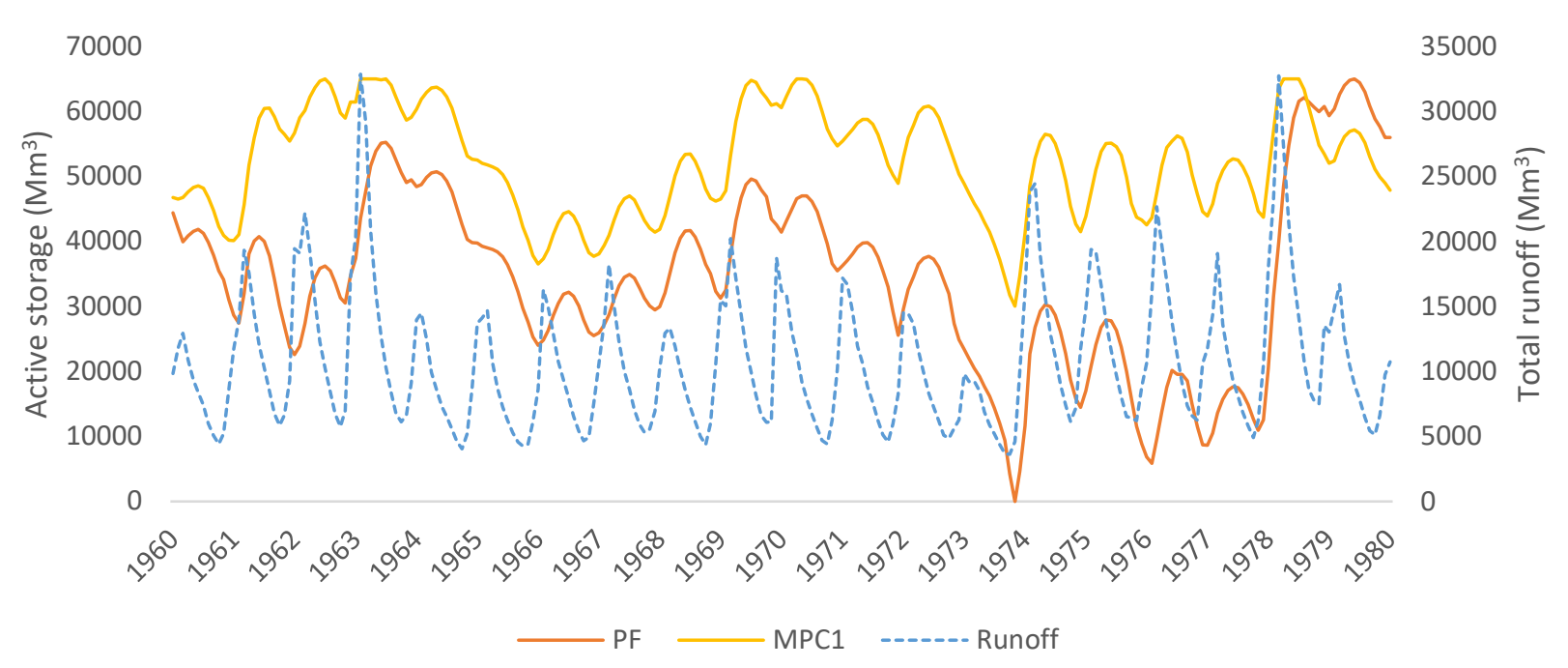

Figure 2. Comparing simulated reservoir management of Kariba dam using perfect foresight and MPC. MPC1 represent the reservoir storage for the MPC framework with a perfect forecast horizon of one month (the current month), PF denotes the perfect foresight framework (equivalent to a perfect forecast horizon of 40 years).

\subsection{Economic evaluation of the infrastructure investments}

Table 1. Infrastructure investments valuation with the perfect foresight and MPC framework for different climate change scenarios.

\begin{tabular}{llll}
$\begin{array}{c}\text { Value of infrastructure } \\
\text { (M\$/year) }\end{array}$ & \multicolumn{1}{c}{ PF } & \multicolumn{1}{c}{ MPC12 } & \multicolumn{1}{c}{ MPC1 } \\
\hline Wettest climate & 1989 & $1994(0 \%)$ & $1960(-1 \%)$ \\
Semiwet climate & 2005 & $1995(0 \%)$ & $1906(-5 \%)$ \\
Semidry climate & 1970 & $1940(-2 \%)$ & $1880(-5 \%)$ \\
Driest climate & 1751 & $1704(-3 \%)$ & $1548(-12 \%)$
\end{tabular}

Table 1 represents the value of the water infrastructure development plan for the different climate change scenarios and the different frameworks. We evaluate how various assumptions about the availability of knowledge about the future affect the economic evaluation of infrastructure based on with/without analysis. PF represents the perfect foresight framework (equivalent to a perfect forecast of 40 years), MPC1 represent the MPC framework where hydrological conditions are known for the current month only and future conditions are forecasted, and MPC12 represents the MPC framework with a (theoretical) perfect forecast of 12 months. The perfect foresight assumption leads to higher valuation of the infrastructure development plan (Table 1). The difference can be explained by less water being used for irrigation and less optimal crop choice leading to lower agriculture benefits, and less valuable hydropower production in the MPC framework (Table 2). Total hydropower production is higher in the MPC than in the perfect foresight framework, which is partially due to less water consumption by agriculture. However, the power production is less stable, as indicated by the lower firm hydropower production (hydropower available $95 \%$ of the months at the scale of the hydropower plant). Therefore, the hydropower investments are not able to replace as much thermal power investments as in the perfect foresight framework and energy benefits are reduced (Table 2).

The different climate change scenarios implicate different levels of water scarcity. In the present climate, with the present water infrastructure, net water consumption is around $11 \%$ of the available runoff (Payet-Burin et al. 2019). Considering the water infrastructure investments, it is around $16 \%$ for the present climate, and varies from 11 to $35 \%$ for the four climate change scenarios. In a more water scarce scenario, the perfect foresight assumption has more impact on the valuation of the infrastructure investments: the difference between the perfect foresight and MPC1 framework varies from $1 \%$ to $12 \%$ from the wettest to the driest climate scenario 
(Table 1). The forecast quality is also found to play an important role, as a perfect forecast of 12 months is found almost equivalent to a perfect foresight framework for low water scarcity (Table 1).

Table 2. Difference in key indicators before and after investments for the driest climate change scenario.

\begin{tabular}{lrr}
\multicolumn{1}{c}{ Indicators - driest climate } & \multicolumn{1}{c}{ PF } & \multicolumn{1}{c}{ MPC1 } \\
\hline Hydropower production (GWh/year) & 19784 & 20005 \\
Firm hydropower (GWh/month) & 970 & 580 \\
Generic power investments (MW) & -2612 & -2188 \\
Energy benefits (M\$/year) & $\mathbf{8 2 3}$ & $\mathbf{7 9 4}$ \\
Net irrigation consumption (Mm³/year) & 5127 & 4814 \\
Agriculture benefits (M\$/year) & $\mathbf{9 2 9}$ & $\mathbf{7 5 1}$
\end{tabular}

\section{CONCLUSIONS}

We show how a Model Predictive Control (MPC) framework can be used to represent limited knowledge about the future in a perfect foresight optimization model. In the Zambezi river basin study case, we use the MPC framework to quantify the effect of the perfect foresight assumption on simulated infrastructure management and on the valuation of hydropower and irrigation investments. We find significant differences between the perfect foresight and MPC frameworks in the valuation of the hydropower and irrigation investments. By valuating the investments in four different climate change scenarios, we show that the impact of the perfect foresight assumption is higher for water scarce contexts.

\section{ACKNOWLEDGEMENTS}

Innovation Fund Denmark, COWIfonden, and COWI A/S founded the Industrial PhD project in which this research was carried out.

\section{REFERENCES}

Albrecht, T. R., Crootof, A. and Scott, C. A.: The Water-Energy-Food Nexus : A systematic review of methods for nexus assessment OPEN ACCESS The Water-Energy-Food Nexus : A systematic review of methods for nexus assessment, Environ. Res. Lett., 13, 1-26, doi:10.1088/1748-9326/aaa9c6, 2018.

Bird, K. and Shepherd, A.: Livelihoods and chronic poverty in semi-arid Zimbabwe, World Dev., 31(3), 591-610, doi:10.1016/S0305-750X(02)00220-6, 2003.

Cervigni, R., Liden, R., Neumann, J. E. and Strzepek, K. M.: Enhancing the Climate Resilience of Africa's Infrastructure: The Power and Water Sectors. [online] Available from: https://openknowledge.worldbank.org/handle/10986/21875, 2015.

Davidsen, C., Pereira-Cardenal, S. J., Liu, S., Mo, X., Rosbjerg, D. and Bauer-Gottwein, P.: Using Stochastic Dynamic Programming to Support Water Resources Management in the Ziya River Basin, China, J. Water Resour. Plan. Manag., 10.1061/(A, doi:10.1061/(ASCE)WR.1943-5452.0000482., 2014.

FAO: FAOSTAT, [online] Available from: http://www.fao.org/faostat/en/\#data/QC (Accessed 27 July 2018), 2018.

Fischer, G., Velthuizen, H., Shah, M. and Nachtergaele, F.: Global Agro-ecological Assessment for Agriculture in the 21st Century: Methodology and Results., 2002.

Harou, J. J., Pulido-Velazquez, M., Rosenberg, D. E., Medellín-Azuara, J., Lund, J. R. and Howitt, R. E.: Hydroeconomic models: Concepts, design, applications, and future prospects, J. Hydrol., 375(3-4), 627-643, doi:10.1016/j.jhydrol.2009.06.037, 2009.

Heaps, C. G.: Long-range Energy Alternatives Planning (LEAP) system, [online] Available from: https://www.energycommunity.org, 2016.

Howells, M., Hermann, S., Welsch, M., Bazilian, M., Segerström, R., Alfstad, T., Gielen, D., Rogner, H., Fischer, G., Van Velthuizen, H., Wiberg, D., Young, C., Alexander Roehrl, R., Mueller, A., Steduto, P. and Ramma, I.: Integrated analysis of climate change, land-use, energy and water strategies, Nat. Clim. Chang., 3(7), 621-626, doi:10.1038/nclimate1789, 2013.

Kahil, T., Parkinson, S., Satoh, Y., Greve, P., Burek, P., Veldkamp, T. I. E., Burtscher, R., Byers, E., Djilali, N., Fischer, G., Krey, V., Langan, S., Riahi, K., Tramberend, S. and Wada, Y.: A continental-scale hydroeconomic model for integrating water-energy-land nexus solutions, Water Resour. Res., doi:10.1029/2017WR022478, 2018.

Keppo, I. and Strubegger, M.: Short term decisions for long term problems - The effect of foresight on model based energy systems analysis, Energy, 35(5), 2033-2042, doi:10.1016/j.energy.2010.01.019, 2010. 
Khan, Z., Linares, P., Rutten, M., Parkinson, S., Johnson, N. and García-González, J.: Spatial and temporal synchronization of water and energy systems: Towards a single integrated optimization model for long-term resource planning, Appl. Energy, 210, 499-517, doi:10.1016/j.apenergy.2017.05.003, 2018.

Loucks, D. P., Beek, E. Van and Van Beek, E.: 00 Water Resources Systems Planning and Management and Applications, Water Resour. Plan. Manag., 2-37, 2005.

Payet-Burin, R., Kromann, M., Pereira-Cardenal, S., Strzepek, K. and Bauer-Gottwein, P.: WHAT-IF: an opensource decision support tool for water infrastructure investment planning within the Water-Energy-FoodClimate Nexus, Hydrol. Earth Syst. Sci. Discuss., (April), 1-49, doi:10.5194/hess-2019-167, 2019.

Pereira-Cardenal, S. J., Mo, B., Gjelsvik, A., Riegels, N. D., Arnbjerg-Nielsen, K. and Bauer-Gottwein, P.: Joint optimization of regional water-power systems, Adv. Water Resour., 92, 200-207, doi:10.1016/j.advwatres.2016.04.004, 2016.

SADC, ZAMCOM and SARDC: Zambezi Environmental Outlook, Harare, Gaborone., 2015.

Sahu, R. K.: Optimal Reservoir Operation using Stochastic Model Predictive Control Signature redacted CoDirector, Computation for Design and Optimization LIBRARIES ARCHNES, 2016.

Tilmant, A., Kinzelbach, W., Juizo, D., Beevers, L., Senn, D. and Casarotto, C.: Economic valuation of benefits and costs associated with the coordinated development and management of the Zambezi river basin, Water Policy, 14(3), 490-508, doi:10.2166/wp.2011.189, 2012.

United Nations: Transforming our world: the 2030 Agenda for Sustainable Development, Gen. Assem. 70 Sess., 16301(October), 1-35, doi:10.1007/s13398-014-0173-7.2, 2015.

World Bank: The Zambezi River Basin, World Bank, 4, 1-202, doi:10.4324/9781315282053, 2010.

Yates, D., Sieber, J., Purkey, D. and Huber-Lee, A.: WEAP21 - A demand-, priority-, and preference-driven water planning model. Part 1: Model characteristics, Water Int., 30(4), 487-500, doi:10.1080/02508060508691893, 2005. 